\title{
Foucault e a "discursividade" do Direito Penal contemporâneo
}

\author{
Luana de Carvalho Silva Gusso ${ }^{1}$ \\ Rodrigo Bueno Gusso ${ }^{2}$
}

\begin{abstract}
Resumo: O artigo versa realiza uma discussão teórica sobre a "discursividade" do direito penal a partir do olhar de Michel Foucault em seu texto "Eu, Pierre Rivière, que degolei minha mãe, minha irmã e meu irmão... um caso de parricídio do século XIX". Nesse sentido, aborda as diferentes estratégias ou mecânicas punitivas que se estabelecem na modernidade, desde "mecânica legal" da organização jurídica, da Idade Média, estabelecida pelo "princípio da soberania" e "da gládio", até o momento histórico em que cedeu espaço para a emergência de uma nova organização política. Uma organização não mais pautada pela possibilidade de dominação e total disposição dos corpos-súditos, mas sim, na política de rejeição ao absolutismo do poder monárquico com a nova formação da ideia do contrato social, ou seja, na determinação dos limites do poder soberano. Sob o discurso da "humanização" do direito de punir, afastouse o direito de morte do soberano, mas agora, sob a égide, não menos perversa, do direito de exclusão. Esses fenômenos de transformação inauguram uma nova era, onde o controle penal como mecanismo de exclusão social, seus discursos e práticas, perpetua até os dias atuais. Assim, busca-se, mediante uma revisão de literatura bibliográfica, possibilitar uma análise dos micropoderes normalizadores desse novo contexto de poder, no nível relacional das práticas diárias, lentamente desenvolvida pelas normas disciplinadoras, que se interessa mais pela produção (ou controle) da vida do que na sua repressão. Nessa linha, o exemplo do texto de Pierre Rivière é marcante para uma reflexão sobre como o direito penal pode ser mobilizado por diferentes estratégias de saber e de poder, promovendo diferentes modelos de uso do corpo humano a serviço de estratégias de poder.
\end{abstract}

Palavras-chaves: Direito Penal, Poder Normalizador, Exclusão Social

\footnotetext{
${ }^{1}$ Professora do Curso de Graduação e Pós-Graduação em Direito e do Programa de Pós-Graduação em Patrimônio Cultural e Sociedade da Universidade da Região de Joinville- UNIVILLE. É Pós-Doutora em Direito pela Universidade de Coimbra e Centro de Estudos em Dirietos Humanos - Ius Gentium Conimbrigae - na área de Democracia e Direitos Humanos (2013), com Mestrado (2008) e Doutorado em Direito do Estado pelo Programa de Pós-Graduação em Direito da Universidade Federal do Paraná (2012). Pesquisadora com experiência nas áreas de Direitos Culturais, Patrimônio Cultural, Criminologia, História do Direito, Direito Penal e Direitos Humanos, com foco no estudo do Controle Social e da Violência, da Cultura e da Memória . É graduada em Direito pela Pontifícia Universidade Católica do Paraná (PUC-PR) (2005) e em Psicologia pela Universidade Federal do Paraná (2005). Especialista em Direito Penal e em Criminologia pelo ICPC - UFPR (2006). Advogada. Email: lu_anacarvalho@yahoo.com.br

2 Pós-Doutor pela Faculdade de Direito da Universidade de Coimbra, Portugal; Doutor em Sociologia pela Universidade Federal do Paraná, UFPR, temática de pesquisa: controle social, crime e punição. Mestre em Direito pela Universidade do Vale do Itajaí-Sc, UNIVALI-SC. Especialista em Segurança Pública pela Pontifícia Universidade Católica do Rio Grande do Sul, PUC-RS. Delegado de Polícia Civil do Estado de Santa Catarina, Professor titular da Academia da Polícia Civil Sc. Professor de cursos de graduação, pós-graduação e formação de policiais civis, militares, guardas municipais e agentes penitenciários.Email gusso@gusso.com.br
} 
Revista NEP, Núcleo de Estudos Paranaenses, Curitiba, v.4, n.2, dez. 2018

\title{
Foucault and the "discursivity" of contemporary law
}

\begin{abstract}
This paper discusses a theoretical discussion about the "discursivity" of criminal law from the perspective of Michel Foucault in his text: "I, Pierre Rivière, who deviled my mother, sister and brother ... a case of parricide of the century XIX ". In this sense, it approaches the different punitive strategies or mechanics established in modernity, from the "legal mechanics" of juridical organization, from the Middle Ages, established by the "principle of sovereignty" and "of the glory", until the historical moment in which space for the emergence of a new political organization. An organization no longer ruled by the possibility of domination and total disposition of the subject bodies, but in the policy of rejecting the absolutism of monarchical power with the new formation of the idea of the social contract, that is, in determining the limits of sovereign power. Under the discourse of the "humanization" of the right to punish, the right of death of the sovereign was withdrawn, but now, under the aegis, no less perverse, of the right of exclusion. These phenomena of transformation inaugurate a new era, where criminal control as a mechanism of social exclusion, its discourses and practices, perpetuates until the present day. Thus, through a review of bibliographical literature, it is possible to analyze the micro power normalizers of this new power context, in the relational level of daily practices, slowly developed by disciplinary norms, that is more interested in the production (or control) of life than in their repression. In this line, the example of Pierre Rivière's text is striking for a reflection on how criminal law can be mobilized by different strategies of knowledge and power, promoting different models of use of the human body at the service of strategies of power.
\end{abstract}

Key-words: Penal Law, Normalizing Power, Social Exclusion

\section{Introdução}

Na aula de 14 de janeiro de janeiro de 1976, no curso Em Defesa da Sociedade, Foucault denuncia a necessidade de se buscar um "direito novo", liberto ao mesmo tempo de um princípio da soberania e "antidisciplinar" como forma de lutar contra o tipo de poder desenhado nas sociedades de normalização ${ }^{3}$. Essa possibilidade de um "direito novo" constitui para Fonseca a terceira imagem assumida pelo direito nas reflexões de Foucault ${ }^{4}$.

A primeira imagem do direito aparece relacionada à mecânica legal, ou seja, o direito identificado com a legalidade, com a elaboração do discurso jurídico pautado pelo “princípio de soberania”. Destaca, portanto, como nos edifícios jurídicos da Idade Média a grande questão para o universo "legal" é a inscrição da soberania do rei numa ordem de legitimidade. Um princípio de soberania marcado pelo "direito de gládio" e pela possibilidade de dominação e total disposição dos corpos-súditos.

\footnotetext{
${ }^{3}$ FOUCAULT, Michel. Em defesa da Sociedade, p. 47.

${ }^{4}$ FONSECA, Marcio Alves. Michel Foucault e o Direito, p. 240.
} 
Revista NEP, Núcleo de Estudos Paranaenses, Curitiba, v.4, n.2, dez. 2018

Esse discurso jurídico do "gládio" é transformado pela emergência de uma nova organização política de rejeição ao absolutismo do poder régio com a formação de uma ideia de contrato. A organização jurídica "contratualista" ainda estava centralizada no "princípio de soberania", entretanto, afastou-se da preocupação com a legitimidade para focar-se na determinação dos limites do poder soberano. O contrato aparece como o principal instrumento jurídico de limitação do poder "soberano" e de garantia para os sujeitos de direito, os cidadãos signatários do pacto social. O direito de "morte" soberano encontrou os princípios reformadores e "humanitários" do direito de punir, convertendo a pena-suplício em pena de exclusão, de separação ou segregação do convívio social.

Desse modo, segundo Fonseca, a imagem do direito como legalidade relacionada com as demandas do "princípio de soberania" deixou diante do "contrato" sua forma de legitimação da dominação de fato exercida pelo rei, para se dissolver em uma preocupação com os direitos "legítimos de soberania" e a "obrigação legal de obediência". A obediência já não era mais submetida à violência do corpo, mas a um princípio de direito. O direito da "morte" lentamente encontra a "vida" como novo destino de poder.

Todavia, a analítica do poder proposta por Foucault deixa em suspenso a abordagem do poder segundo a questão de "soberania e legitimidade", para desvelar os micropoderes normalizadores e seu impacto na construção das "realidades" social e individual.

Com isso, Foucault afasta-se dos modelos "legais" da análise do poder, para buscar no nível das práticas diárias, nos pequenos enfrentamentos e nas sujeições um poder assentado no nível relacional, mais interessado na produção na vida humana do que na sua repressão. São as disciplinas e a consequente organização de uma sociedade de "normalização".

A própria imagem do direito ganha um novo aporte. Sob as disciplinas, os usos do direito tomam outros rumos, ou seja, são capturados pela necessidade de "normalização" e convertidos em uma das múltiplas formas de dominação 5 .

\footnotetext{
${ }^{5}$ FONSECA, Marcio Alves. Michel Foucault e o Direito, p. 243.
} 
Revista NEP, Núcleo de Estudos Paranaenses, Curitiba, v.4, n.2, dez. 2018

Isso não significou que mediante as estratégias do poder disciplinar o direito tenha perdido sua conexão com o princípio de soberania ou tenha deixado seu lugar como instância de poder nas sociedades. O discurso jurídico não só sobreviveu como expandiu seus "domínios" e seus efeitos sobre a nova sociedade burguesa. O exemplo disso é a crescente demanda pela elaboração de Codificações e, por conseguinte, da elaboração da dogmática e de uma jurisprudência ${ }^{6}$.

Mas tal "expansão" legal e o próprio princípio de soberania são investidos pelos mecanismos de normalização. Foucault define o exercício de poder nas sociedades de "normalização" nos limites entre o direito de soberania e a mecânica polimorfa da disciplina. O discurso legal, o direito público e os limites da soberania dos Estados encontram-se permeados pelos micropoderes de dominação disciplinar, ativando um mecanismo de assujeitamento dos indivíduos por todo corpo social. Estratégias diferentes, um só objetivo: a dominação dos corpos.

O Direito Penal é uma das esferas em que essa colonização do poder jurídico pelas disciplinas aparece com certo vigor. Afinal, é na formação da responsabilidade penal (a culpabilidade) que todo um saber disciplinar (as ciências humanas e seu laudos, perícias e apontamentos) pode aparecer como um dos principais fundamentos na compreensão e na elaboração de uma "verdade" do homem: o homem criminoso.

Para Foucault, um modo de promover a resistência aos modelos de dominação e de sujeição dos corpos pelas mecânicas de poder "soberano" e "normalizador" envolvidas nos discursos jurídicos é a construção de um novo modelo de direito: um direito novo. Para Fonseca, o "direito novo" não deve ser confundido com as outras duas imagens do direito, mas com um novo momento do mundo jurídico capaz de oferecer uma saída para a "normalização" distinta da absoluta "legalização" da teoria da soberania.

Foucault não definiu ou deu detalhes sobre o funcionamento deste "direito novo". Pelo acompanhamento de suas reflexões, podemos identificar apenas algumas ideias ou críticas que podem conter uma espécie noção geral dos pequenos enfrentamos dos dramas jurídicos, responsáveis por fazer aparecer uma forma de direito de "resistência".

\footnotetext{
${ }^{6}$ Como os Códigos Napoleônicos: Código Civil de 1804, o Código de Instrução Criminal de 1808 e o Código Penal de 1810; no Brasil, destaca-se a elaboração do Código Penal do Império em 1830.
} 
Revista NEP, Núcleo de Estudos Paranaenses, Curitiba, v.4, n.2, dez. 2018

\section{Uma crítica aos discursos legal e disciplinar: $O$ exemplo de Pierre Rivière}

O lugar escolhido para tentar compreender esse novo modelo de direito, particularmente do Direito Penal, é um pequeno livro organizado por Foucault sobre um acontecimento que à primeira vista nada tem de excepcional: o crime de Pierre Rivière ${ }^{7}$.

O crime - e, posteriormente, o desenvolvimento do "caso" ou do "dossiê" - ilustra bem o foco das preocupações foucaultianas nos ditos "discursos marginais", na descoberta dos pequenos dramas reais do cotidiano humano, da narrativa da "vida infame" dos corpos e sua trajetória nas demandas de poder. Com a "descoberta" do seu "caso", a trajetória de Jean-Pierre Rivière rompeu seu silêncio histórico para como um fragmento de realidade aparecer como uma nova possibilidade crítica aos discursos legal e disciplinar.

Como outras tantas historietas (fragmentos de vida) narradas por Foucault em sua trajetória (como, por exemplo, o suplício de Damiens), a vida de Pierre Rivière nada se destaca das demais em seu tempo, até a ocorrência de um acontecimento fundamental: seu crime. Era um jovem de 20 anos, residente na aldeia de La Faucterie, na região rural de Calvados, na Normandia. No dia 3 de junho de 1835, Pierre cometeu um triplo assassinato: parricídio e fratricídio; ao matar a mãe e dois irmãos menores (um menino de sete anos e uma menina de dezoito) a golpes de faca (ou foice). Foi julgado e condenado à morte em 12 de novembro de 1836, mas sua pena foi transformada em prisão perpétua devido a um indulto real. Suicidou-se em 20 de outubro de 1840 na Prison Centrale de Beaulieu, lugar em que cumpria sua pena.

O caso Rivière foi recuperado por Foucault nos Annales d'hygiène publique et de édecinelégale de 1836, quando ele buscava estudar a história das relações entre a psiquiatria e a justiça. E o "dossiê" Rivière revelou-se muito especial na elucidação das relações intrínsecas entre os saberes "normalizadores" das ciências humanas e o modelo de justiça penal de sua época.

\footnotetext{
${ }^{7}$ FOUCAULT, Michel. (Coord). Eu, Pierre Rivière, que degolei minha mãe, minha irmã e meu irmão ...um caso de parricídio do século XIX. Apresentado por Michel Foucault; Trad. Denise Lezan de Almeida. Rio de Janeiro: Graal, 1982, p. IX.
} 
Revista NEP, Núcleo de Estudos Paranaenses, Curitiba, v.4, n.2, dez. 2018

Para Foucault, não é o tipo de crime cometido por Rivière que destaca seu "dossiêe" como um acontecimento. De fato, os crimes de parricídio - ao contrário dos dias de hoje - eram numerosos nos tribunais do júri e já não causavam tanta comoção na opinião pública da época. O ponto fundamental contido nos fragmentos de vida desse dossiê são alguns "elementos extraordinários" destacados por Foucault, como a existência de vários registros médicos de diferentes origens (de diferentes médicos e instituições) que traziam conclusões diferentes (e às vezes opostas) sobre o caso ${ }^{8}$; o registro detalhado das peças judiciais, como os interrogatórios, a oitiva de testemunhas sobre o modo de vida de Pierre e sua "personalidade" que instruíram o processo-crime; e a existência de uma espécie de memorial escrito pelo próprio Pierre, em que ele mesmo narra com detalhes seu crime e fornece uma espécie de explicação sobre suas "causas".

A importância do caso Pierre para Foucault é a possibilidade de observar o cruzamento e o enfrentamento entre esses discursos oriundos de posições de saber e poder diferentes. Sobre um mesmo acontecimento são construídas diferentes verdades que não se sobrepõem umas as outras, mas se integram por meio das suas contradições aos mecanismos de poder envolvidos nesse acontecimento, o que transforma o caso Pierre não em uma obra, mas em "uma luta singular, um confronto, uma relação de poder, uma batalha de discursos e através do discurso". 9

Essa batalha discursiva é composta pela multiplicidade das verdades construídas nos discursos coletados em que o grande final seria o estabelecimento de qual discurso era o mais "certo", qual discurso era capaz de estabelecer-se como a "verdade" sobre as outras "verdades".

Assim, são coletados os discursos das "testemunhas" da vida de Pierre e de seu "crime". Um discurso que releva os saberes e poderes de seus vizinhos, das autoridades de sua aldeia, dos membros de sua própria família. Pierre pode ser apresentado como um jovem "normal", um pouco "calado demais", de "gênio obstinado", "extravagante na imaginação", "ridículo", "infantill, "que gostava de matar passarinhos" ou que "não gostava de gatos", pelos habitantes da sua aldeia. As testemunhas de seu crime descrevem-no no momento de seu ato como "alguém calmo", que "conversou

\footnotetext{
${ }^{8}$ FOUCAULT, Michel. (Coord). Eu, Pierre Rivière, que degolei minha mãe, minha irmã e meu irmão, p. IX.

${ }^{9}$ FOUCAULT, Michel. (Coord). Eu, Pierre Rivière, que degolei minha mãe, minha irmã e meu irmão, p. XII.
} 
Revista NEP, Núcleo de Estudos Paranaenses, Curitiba, v.4, n.2, dez. 2018

serenamente após o ocorrido", que quando questionado sobre "o que havia feito", apenas respondeu "acabo de livrar meu pai de todas suas infelicidades"10.

Há os discursos coletados durante a instrução criminal. O discurso da promotoria o acusando de um crime bárbaro, dos policiais que o encontraram vagando na floresta após seu ato, dos seus advogados atestando sua defesa por meio da constatação de sua "insanidade" e, ainda, de sua própria fala nos interrogatórios judiciais, a sentença de morte promulgada pelo juiz e o posterior indulto concedido pelo rei, livrando-o da morte pela forca, mas o aprisionando em vida para sempre ${ }^{11}$.

$\mathrm{E}$ os discursos médicos. O caso Rivière chama a atenção pela quantidade e qualidade dos laudos e opiniões médicas sobre sua saúde e estado mental e, principalmente, pela discordância latente nesses discursos. São três pareceres médicolegais assinados por diferentes médicos. O primeiro feito pelo médico da província, Dr. Morin, que nada via ou sabia de Pierre que poderia identificá-lo como um alienado, apenas possuía um "gênio obstinado"12. O segundo laudo é do Dr. Bouchard, que o atendeu já na prisão e atestava suas boas condições de saúde, sua "boa constituição" e seu "ar tranquilo, mas sombrio", de temperamento "bilicoso-melancólico". ${ }^{13}$ Nesse discurso, Pierre é apresentado como um jovem mais calado, mas sem qualquer sinal de alienação mental. O terceiro parecer é fornecido pelo então importante e famoso Dr. Vastel a pedido do advogado de defesa. Em seu memorial sobre o "caso" Pierre, o Dr. Vastel diagnostica uma séria alienação mental ocasionada desde sua infância, com raízes hereditárias, manifestada pouco antes de seu crime. Nesse discurso, a causa do crime só poderia ser sua enfermidade, razão pela qual Pierre demostrou-se arrependido depois, escrevendo suas memórias. Pierre se não é culpado é, na opinião do especialista, perigoso e deve ser isolado da sociedade ${ }^{14}$.

No centro das definições médicas sobre o estado de alienação mental de Pierre estavam as divergências e descobertas do saber psiquiátrico sobre a loucura. Era a época dos debates sobre a "monomania" como a espécie por excelência de alienação grave, que

\footnotetext{
${ }^{10}$ FOUCAULT, Michel. (Coord). Eu, Pierre Rivière, que degolei minha mãe, minha irmã e meu irmão, p, 37.

${ }^{11}$ FOUCAULT, Michel. (Coord). Eu, Pierre Rivière, que degolei minha mãe, minha irmã e meu irmão, p.113.

${ }^{12}$ FOUCAULT, Michel. (Coord). Eu, Pierre Rivière, que degolei minha mãe, minha irmã e meu irmão, p. 24.

${ }^{13}$ FOUCAULT, Michel. (Coord). Eu, Pierre Rivière, que degolei minha mãe, minha irmã e meu irmão, p.114.

${ }^{14}$ FOUCAULT, Michel. (Coord). Eu, Pierre Rivière, que degolei minha mãe, minha irmã e meu irmão, p. 125.
} 
Revista NEP, Núcleo de Estudos Paranaenses, Curitiba, v.4, n.2, dez. 2018

só poderia ser tratada no interior dos manicômios. O caso Pierre poderia ser mais um discurso de legitimação da "monomania" e, por conseguinte, do próprio saber-poder da psiquiatria $^{15}$.

O discurso que mais chama a atenção nesse "caso" é um memorial redigido pelo próprio Pierre durante sua prisão (a data de início desse memorial posta em dúvida, pois o próprio Pierre afirma que iniciou a escrita antes mesmo de ser preso). Pierre escreve uma espécie de "memórias" em que explicaria as "razões" do seu ato criminoso. Inicia seu memorial pela seguinte frase: "Eu, Pierre Rivière, que degolei minha mãe, minha irmã e meu irmão, e querendo tornar conhecidos os motivos de meu crime que me levaram a esta ação, escrevi toda a vida que meu pai e minha mãe levaram juntos durante seu casamento ${ }^{16}$."

Tal memorial é dividido em duas partes. Na primeira, Pierre narra os dissabores de seu pai desde o casamento com sua mãe, a responsável, segundo Pierre, pela infelicidade do casal nos anos de 1813 a 1835. Pierre fornece detalhes do contrato de casamento de seus pais, do dia-a-dia do casal, das brigas, da gravidez de sua mãe e do tratamento e educação dos filhos. Destaca o amor e a pena que sentia pela situação do pai e a raiva das atitudes de sua mãe. Descreve o amor que os filhos mais novos sentiam pela mãe. Na segunda parte, Pierre dedica-se a explicar seu "caráter e os pensamentos" que teceu antes de cometer tal ato. Pierre passa a narrar sua própria infância, sua relação com o pai, com a religião e a solidão. Como se sentia diante do mundo de si mesmo, como cresceu nele a necessidade de se "elevar", de fazer "barulho no mundo", e se "encher de glória" na libertação do seu pai. E seu crime; como começou a planejar sua ação escolhendo o melhor momento, a melhor forma e suas vítimas. Como mandou afiar sua foice e pensou em escrever uma carta de explicação para o pai. E como planejou seu suicídio.

Neste memorial, Pierre escreve passo a passo cada momento de seu ato até seu grande desfecho: sua morte. Todos os momentos são cuidadosamente relacionados formando uma espécie de teia tramada por suas verdades. Pierre, que amava o pai e não

\footnotetext{
${ }^{15}$ FOUCAULT, Michel. (Coord). Eu, Pierre Rivière, que degolei minha mãe, minha irmã e meu irmão, p. XI.

${ }^{16}$ FOUCAULT, Michel. (Coord). Eu, Pierre Rivière, que degolei minha mãe, minha irmã e meu irmão, p. 51.
} 
Revista NEP, Núcleo de Estudos Paranaenses, Curitiba, v.4, n.2, dez. 2018

suportava vê-lo sofrer, matou sua família, escolhendo ser odiado do que perdoado. Queria morrer, mas acabou fugindo, vivendo durante aproximadamente um mês pelas estradas e pela floresta, uma vida de isolamento que sempre desejou. Acabou preso sem resistência. Disse aos comissários que já esperava por isso.

Enfrentou toda a instrução da justiça penal consciente de seu discurso e da sua verdade. Uma verdade que não foi capturada nem pela justiça nem pela psiquiatria. As razões de Pierre só significam algo para Pierre. Sua verdade está nas linhas da produção de seu discurso, que não foram atingidas pela sentença da justiça ou pelo diagnóstico do médico. Pierre não se importou com as consequências "penais" de seu ato, nem pela morte, nem pela prisão. Queria morrer, porque assim o planejou. Acabou se suicidando.

\section{O drama do direito e o conflito de diferentes tipos de discursos pela busca da verdade "incontestável"}

A preciosidade do "dossiê" de Pierre Rivière para o tema do direito é justamente o enfrentamento entre tipos de discursos diferentes no interior das instâncias judiciais. Um caso apresentado por Foucault como um "drama do direito".

As razões da existência deste "drama" são a presença de uma série de elementos do discurso jurídico, tanto em sua imagem "legalizada" quando na sua imagem "normalizada". No caso, fica evidente a batalha entre o discurso legal e o discurso psiquiátrico pelo estabelecimento da verdade "incontestável" do crime, pela melhor explicação do caso Rivière e pela solução mais apropriada para seu dilema.

O caso demonstra abertura ao saber psiquiátrico do Direito Penal como uma possibilidade de melhor ajustamento entre os sujeitos e a lei. Uma abertura conflituosa em que esses discursos se enfrentam pela posição de "verdade". O estabelecimento da "responsabilidade" penal é o centro dos debates desse "drama" do direito. A responsabilidade penal como fundamento da pena, tradicionalmente relacionada ao poder do direito, ao poder do juiz, encontra outra "verdade" no interior da psiquiatria, por meio da requisição de um lugar de poder e saber sobre o homem e seu crime. Assim, a responsabilidade do autor só poderia de fato ser conhecido mediante os saberes médicos, 
Revista NEP, Núcleo de Estudos Paranaenses, Curitiba, v.4, n.2, dez. 2018

os pareceres e laudos "explicativos" que conteriam a "justiça" do homem fornecidas ao juiz.

Uma visão dramática do enfrentamento entre saberes e poderes sobre o destino dos indivíduos. Do Direito Penal como um palco de confronto entre lei e norma, até a leitura do "memorial" de Pierre.

No discurso de Pierre em seu 'memorial' o drama do direito ganha uma nova conotação, ganha um desfecho singularizado pela "tragicidade". Como toda tragédia "grega", o dossiê Rivière, segundo Foucault, traz a possibilidade por meio de suas tramas discursivas, dos seus enfrentamentos mundanos, dos seus múltiplos "rostos" e "verdades", da emergência do "novo". No memorial, Pierre escreve por si mesmo as razões do seu crime, explica, narra, dá sua versão da história construindo um discurso que passa além do poder da lei e da norma. Seu discurso não fica reduzido às questões legais da imputação entre fato e sujeito. E nem ao discurso médico. Não é possível estabelecer se Pierre é louco ou criminoso.

Seu caso coloca em xeque os mecanismos de responsabilização do Direito Penal. Afinal, nem a lei nem a norma são capazes de dizê-lo. O único capaz é ele mesmo quando afirmou "Eu, Pierre Rivière, que degolei minha mãe, minha irmã e meu irmão, e querendo tornar conhecidos os motivos de meu crime que me levaram a esta ação...”. Com sua afirmação, sua descrição, suas razões e sua busca pela morte, Pierre impôs a ele mesmo um limite à sua responsabilidade, uma responsabilidade que não pode ser imposta por um julgamento ou um laudo.

Pierre escapou da lei e da norma, porque elas não dão conta de explicá-lo ou de revelar sua verdade, libertando-se inclusive das amarras da narrativa linear e alegórica. Seu texto não leva em consideração o tempo cronológico ou qualquer outra regra discursiva.

O discurso de Pierre revela uma possibilidade para o próprio sujeito atuar na vida social sem qualquer recurso a uma exterioridade, a um saber constituído ou a um poder constituinte. Ele de alguma forma se apresentou como uma resistência. Um discurso de resistência à trama de poder da lei e da norma, as formas de sujeição e dominação dos indivíduos. 
Revista NEP, Núcleo de Estudos Paranaenses, Curitiba, v.4, n.2, dez. 2018

Nesse sentido, um terceiro uso do direito em Foucault, um novo modelo de direito, seria possível por meio do seu afastamento tanto do modelo legal quanto do modelo normalizador. Um direito pautado pelo fortalecimento de uma atitude crítica dos sujeitos perante o cotidiano, as relações de poder, as imposições do saber, as práticas de governo. Uma atitude crítica que, no exemplo de Pierre, destaca a recusa em ser governado pelos outros, pelo modelo de verdade, de poder, de economia, de crença instituído, mas mediante a consciência de si, da verdade de si. O "governo de si" como a possibilidade de resistência e de construção do novo.

O resgate do "si" pode ser aproximado da tarefa proposta por Kant em seu questionamento sobre "O que é o Esclarecimento?"17. Esclarecer o ser humano é caminhar para a saída de um estado de menoridade intelectual, volitiva, ética ou política, para uma maioridade, para o espaço de reflexão sobre o que "Eu" entendo sobre o conhecimento, sobre a razão, sobre minhas vontades e desejos, sobre a minha verdade. Um estado de independência do olhar impositivo do "outro"18.

Buscar, segundo Foucault, uma nova dimensão ética no "cuidado de si”. ${ }^{19} \mathrm{Em}$ um domínio ético não compreendido como o campo das normas ou valores morais, mas o campo das relações que o indivíduo estabelece consigo mesmo. Daí seu destaque para novas formas de subjetivação que passam necessariamente pela abertura ao estado de bem-estar consigo mesmo. Uma relação resgatada por Foucault nas sociedades antigas da Grécia e Roma.

\section{Considerações finais}

\footnotetext{
${ }^{17}$ KANT, I. Resposta à questão: o que é Esclarecimento? In: MARÇAL, J. Antologia dos textos filosóficos. p. 406-415. Curitiba: SEED-PR, 2009.

${ }^{18}$ FOUCAULT, Michel. O Que São as Luzes? In. FOUCAULT, M. Ditos e Escritos: A Arqueologia das Ciências e a História dos Sistemas de Pensamento. Volume II. Trad. Elisa Monteiro. São Paulo: Forense Universitária, 2002 , p. 338.

${ }^{19}$ FOUCAULT, Michel. História da Sexualidade. O Cuidado de si. Tomo III. $4^{a}$. Edição. Trad. Maria Thereza da Costa Albuquerque. Rio de Janeiro: Graal, 1985.
} 
Revista NEP, Núcleo de Estudos Paranaenses, Curitiba, v.4, n.2, dez. 2018

Foucault não apenas deixa em aberto a estrutura desse (novo) direito antidisciplinar, mas também nos provoca a pensar em um modelo de teoria jurídica (e de responsabilidade penal) para além do domínio e sujeição dos corpos. Para Fonseca, a abertura promovida por Foucault para pensar o novo possibilita a reflexão de um direito sem qualquer referência ao absoluto. Um direito movido pela inquietação e ação refletida e contínua dos seres humanos sobre sua realidade e seu poder. É por meio desse conhecimento refletido que seriamos capazes de reivindicar a pretensão de novos direitos.

Esse "novo" direito passaria pelas pequenas tentativas (ou resistências) construídas todos os dias nas lides dos tribunais, nos cartórios, no interior das penitenciárias a partir de uma "tomada de si", do enfrentamento do si com o outro representado pelos poderes sobre a vida. Dogmaticamente podemos concluir que esse direito "anti-disciplinar" figura como um horizonte perseguido para a valorização da dimensão humana livre das formas de sujeição de nosso tempo.

Mas, isso não significa uma impossibilidade. Um novo sujeito crítico demanda a formação de um novo direito crítico. Dessa forma, o próprio Direito Penal (crítico) poderia ser construído sob bases diferentes daquelas de opressão e violência. Um Direito Penal crítico passa pelo resgate do "humano" ante a violência punitiva. A responsabilidade penal poderia, por fim, ganhar como fundamento e limite um sujeito humano crítico e senhor de si: eticamente responsável porque constrói sua própria verdade e sua própria consciência. Capaz de governar e ser governado porque está finalmente livre das imposições e coerções a sua pessoa. E uma sociedade livre, mas livre dos modelos normalizadores de disciplina para o trabalho e controle da população para o rendimento da economia. Livres da lei que oprime, do saber que condiciona e do poder que sujeita.

\section{Referências}

FONSECA, Marcio Alves. Michel Foucault e o Direito. São Paulo: Max Limonad, 2002.

FOUCAULT, Michel. Em defesa da Sociedade. Trad. Maria Ermantina Galvão. São Paulo: Martins Fontes, 2002. 
N E P Revista NEP, Núcleo de Estudos Paranaenses, Curitiba, v.4, n.2, dez. 2018

FOUCAULT, Michel. (Coord). Eu, Pierre Rivière, que degolei minha mãe, minha irmã e meu irmão ...um caso de parricídio do século XIX. Apresentado por Michel Foucault; Trad. Denise Lezan de Almeida. Rio de Janeiro: Graal, 1982

FOUCAULT, Michel. História da Sexualidade. O Cuidado de si. Tomo III. 4a . Edição. Trad. Maria Thereza da Costa Albuquerque. Rio de Janeiro: Graal, 1985

FOUCAULT, Michel. O Que São as Luzes? In. FOUCAULT, M. Ditos e Escritos: A Arqueologia das Ciências e a História dos Sistemas de Pensamento. Volume II. Trad. Elisa Monteiro. São Paulo: Forense Universitária, 2002

KANT, I. Resposta à questão: o que é Esclarecimento? In: MARÇAL, J. Antologia dos textos filosóficos. p. 406-415. Curitiba: SEED-PR, 2009.

Recebido: 10 set. 2018

Aceito: 16 nov. 2018 